\title{
Temporal variation in the chromosomal structure of a hybrid zone and its relationship to karyotypic repatterning
}

D. D. Shaw, D. J. Coates, M. L. Arnold and P. Wilkinson
Department of Population Biology, Research School of Biological Sciences, Australian National University, Canberra, Australia.

A temporal analysis of the chromosomal structure of the hybrid zone in the grasshopper Caledia captiva has revealed that, over a period of six generations, the position of the zone has remained unchanged when assessed in terms of chromosomal frequencies. In complete contrast however, chromosomal genotypic frequencies have changed dramatically and asymmetrically over the same period. The frequencies of chromosomal heterozygotes have been significantly reduced on one side of the zone accompanied by increases in the frequencies of homozygous metacentric chromosomes. These asymmetrical genotypic changes are also reflected in a complete reversal of the patterns of gametic disequilibria $\left(T r^{2}\right)$ across the zone. It is proposed that undirectional selection has favoured a metacentric karyotype on one side of the zone during a major climatic change.

The structure of the hybrid zone involves two major and independent features. First, as a secondary consequence of hybridisation, recombinational change in $F_{1}$ hybrids disrupts the internal organisation within chromosomes. This results in the production of inviable $\mathrm{F}_{2}$ and backcross progeny and hence, explains the structure of the zone in terms of the sharp change in chromosomal frequencies. Secondly, the asymmetrical nature of the gametic disequilibria between chromosomes represents the direction of selection which favours an acrocentric Torresian karyotype in dry years and a metacentric Moreton karyotype during mesic years. Variation in both chromosome structure and embryonic weight is associated with the predictability of the environment. The acrocentric Torresian karyotype and its associated larger embryos are correlated with a univoltine life history in drier, unpredictable habitats. A similar pattern exists within the Moreton subspecies in the form of a chromosomal cline in S.E. Australia. At the southern limit of this cline the karyotype is totally acrocentric, the life history is univoltine and the embryos are the same weight as the Torresian.

It is speculated that variation in chromosomal structure, in terms of the relationship between centromeres and telomeres, may provide a mechanism for altering cellular phenotype through changes in such factors as replication patterns or chromatin packaging which may act quite independently of the informational content of the chromosome.

\section{INTRODUCTION}

Natural hybridisation between taxa which have diverged in allopatry provides an ideal opportunity to analyse the evolutionary significance of the genetic differentiation which distinguish those taxa. The accumulation of genetic differences during allopatry can involve the processes of natural selection and genetic drift and it is the relative contribution of the former that is considered to form the basis for adaptation within populations (Mayr, 1982). However, attempts to identify the adaptive component of genetic divergence during the speciation process have generally proved more difficult than was initially anticipated and has led to the present controversy between "phyletic gradualism" and "punctuational speciation"
(Levinton and Simon, 1980); Charlesworth et al., 1982; Maynard Smith, 1983).

On the one hand it has been proposed that speciation involves processes quite different from those genetic changes which adapt populations to the local environment. Thus speciation requires a major reorganisation of the genome over very short time periods (Carson, 1973; Gould and Elderidge 1977). In this context, chromosomal rearrangements are directly implicated in the punctuational process as initiators of divergence and rapid speciation (Gould, 1980).

On the other hand, selectionists maintain that an extention of intrapopulational adaptive processes can adequately accommodate the changes necessary for the development of reproductive isolation as a pleiotropic consequence of the gradual 
accumulation of genetic differences (Avise, 1976) or as a secondary feature at the interface boundary between incipient species (Dobzhansky, 1970). In this way, the genome acquires a highly integrated, "functional unity" (Mayr, 1975) in which heterozygous chromosomal rearrangements can play a significant role in the maintenance of relationally balanced or "coadapted" pairs of chromosomes (Dobzhansky, 1950). Fitness is not considered to be an intrinsic property of the rearrangement within the chromosome but rather to result from a coadaptation between two gene complexes on the respective homologues (Pavlovsky and Dobzhansky, 1966).

In complete contrast, the general failure to identify any adaptive function, at the phenotypic level, for the frequent occurrence of homozygosity for chromosomal rearrangements in natural populations has created the singular view that their primary role is to reduce fecundity when heterozygous (Wright, 1941; White, 1978; Lande, 1984). As a consequence, heterozygosity for Robertsonian fusions and pericentric inversions has been proposed as a major component in initiating divergence and the speciation process. This is most clearly illustrated in the stasipatric model of White et al. (1967), and strongly supported by Bush (1975), which proposes that chromosomal rearrangements achieve fixation by chance in very small populations because of the presumed strong underdominance of chromosomal mutations in meiosis during the transient heterozygous phase. (Lande, 1979).

An alternative hypothesis is that homozygosity for chromosomal rearrangements represents an adaptive feature of the genome quite distinct from, and independent of, genic homozygosity. Thus karyotypic structure may represent an adaptive phenotypic trait per se. Such a function for the karyotype has been alluded to by White (1975) as "Karyotypic Orthoselection". However, although this model intuitively suggests that the karyotype may represent an adaptive strategy, no specific examples are provided and no mechanisms proposed.

The grasshopper Caledia captiva is an ideal organism with which to test the concept of an adaptive karyotype since it shows the following features:

(a) A single taxonomic species contains several taxa which are karyotypically divergent (Shaw, 1976).

(b) Two of these taxa-the Moreton and Torresian subspecies-show major chromosomal differentiation in the distribution and abundance of highly repetitive DNA (Arnold et al., 1985) and also differ by a series of pericentric rearrangements which transform the acro- and telocentric chromosomes of the Torresian genome into metacentrics in the Moreton taxon (Moran and Shaw, 1977). Thus chromosomal homozygosity for these alternate forms diagnostically distinguishes the two taxa. Such concerted changes involving most members of the genome cannot be interpreted simply in terms of genetic drift.

(c) The most significant feature of these two chromosomally distinct taxa is that they are only partially reproductively isolated (Shaw and Wilkinson, 1980) and form an extremely narrow zone of hybridisation in S.E. Queensland. Although the zone has been studied in some detail by Moran (1979), and hybrid breakdown among the $F_{2}$ and backcross generations can adequately explain its structure (Shaw and Wilkinson, 1980), no evidence was found in either of these studies to indicate any functional significance for the karyotypic repatterning which distinguish the taxa. Subsequent laboratory analyses by Coates and Shaw (1982) and Shaw et al., (1982) revealed that all of the hybrid breakdown was attributable to intra chromosomal effects caused by major changes to the recombination system in $\mathrm{F}_{1}$ hybrids. This disruption to the internal organisation of the chromosomes conflicted with the results of Moran (1979) who discovered extensive and asymmetrical gametic disequilibrium between nonhomologous chromosomes among samples taken from the hybrid zone. Thus two important features of the zone remain unresolved and paradoxical. First, no adequate explanation of the causes of the asymmetrical gametic disequilibria (interchromosomal effects) could be obtained from the experimental data. Secondly, no evidence was forthcoming to indicate any adaptive significance for the fixed karyotypic differences which distinguish the taxa.

We have resampled the zone six years after the analysis by Moran (1979) and compared the two data sets in terms of the chromosomal structure of the zone. The results indicate that highly significant changes in the genotypic organisation of the zone have occurred over this short time period. Moreover, these changes are correlated with a major climatic perturbation during this time indicating the action of strong directional selection involving most of the genome.

\section{MATERIALS AND METHODS}

Adult grasshoppers were collected from the hybrid zone during February 1983. The samples were taken at 200 metre intervals from six sites (TA, 


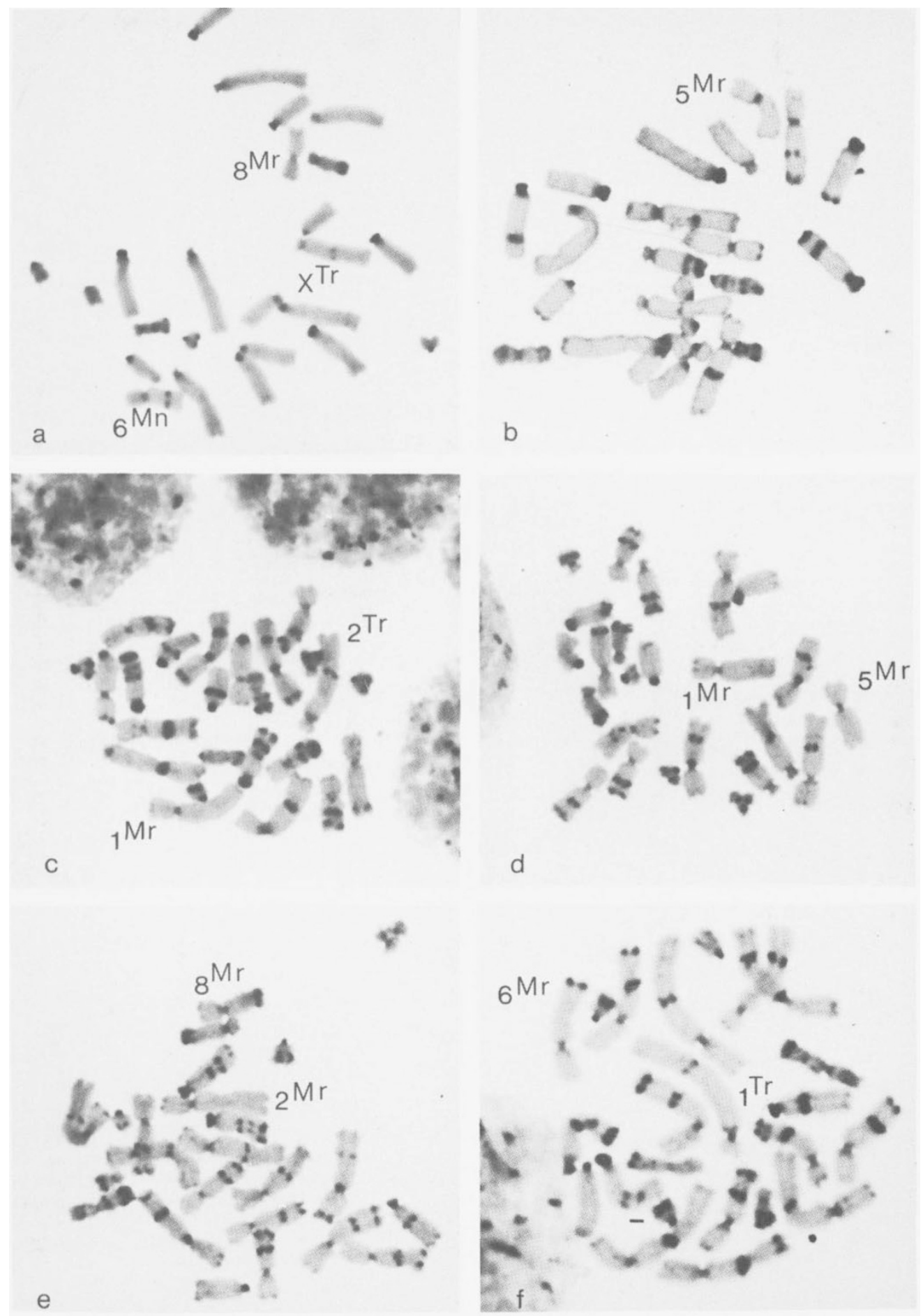

Figure 1 Representative examples of $C$-banded mitoses from individuals within the hybrid zone. (a) TA-2 $q$ a predominantly Torresian individual showing examples of a Moreton recombinant chromosome $8\left(8^{\mathrm{Mr}}\right)$ and a Torresian recombinant $X$ chromosome $\left(X^{\mathrm{Tr}}\right)$. (b) TA-19 showing an unbanded Moreton recombinant $5\left(5^{\mathrm{Mr}}\right)$. (c) TA-49 a predominantly Moreton individual with a recombinant Torresian $2\left(2^{\mathrm{Tr}}\right)$ and a Moreton recombinant $1\left(1^{\mathrm{Mr}}\right)$. (d) TA-3 9 showing Moreton recombinant chromosome $1\left(1^{\mathrm{Mr}}\right)$ and a recombinant Moreton $5\left(5^{\mathrm{Mr}}\right)$. (e) TA-3 9 with a Moreton recombinant $8\left(8^{\mathrm{Mr}}\right)$ and a Moreton recombinant $2\left(2^{\mathrm{Mr}}\right)$. (f) a predominantly Moreton male from TA-3 with a recombinant Torresian chromosome $1\left(1^{\mathrm{Tr}}\right)$ and a Moreton recombinant chromosome $\left(6\left(6^{\mathrm{Mr}}\right)\right.$. 


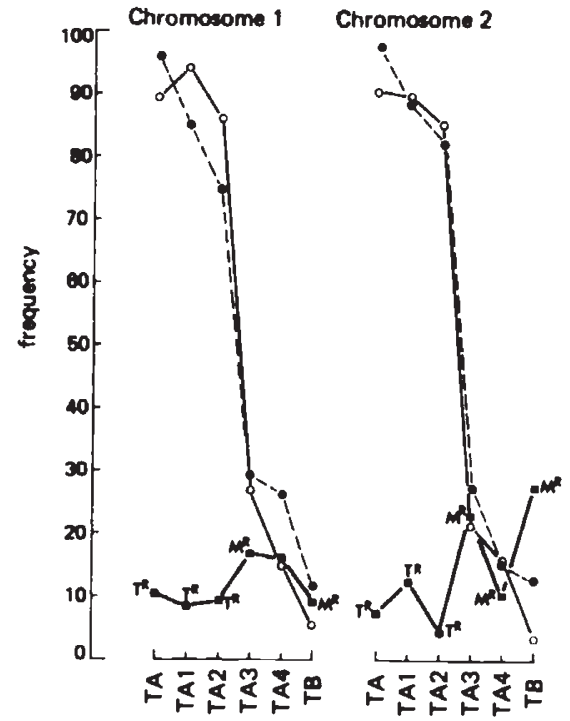

a

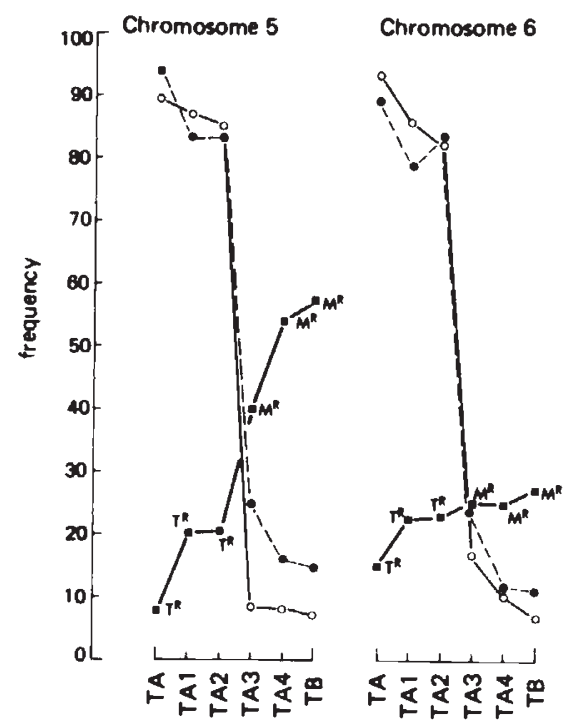

C

Figure 2a-c The frequency distributions of chromosomes 1, 2, X4, 5 and 6 across the hybrid zone. The distance between each sample site (TA to TB) is 200 metres. Note the concordance of all the chromosome frequencies between years with the major change in frequency between TA-2 and TA-3. $\mathrm{T}^{\mathrm{R}}$ and $\mathrm{M}^{\mathrm{R}}$ represent the frequencies of Torresian recombinant and Moreton recombinant chromosomes at each sample site. Note the overall higher frequencies of recombinants on the Moreton side of the zone $\left(-\ldots 1977, \_1983\right)$.

TA-1 to TA-4, TB) along a transect at identical locations to those sampled by Moran in 1977 (see fig. 2 in Moran 1979). Between 30 and 40 individuals were collected at each location. Grasshoppers were maintained in the laboratory under controlled environmental conditions and egg pods were collected daily from each of the transect

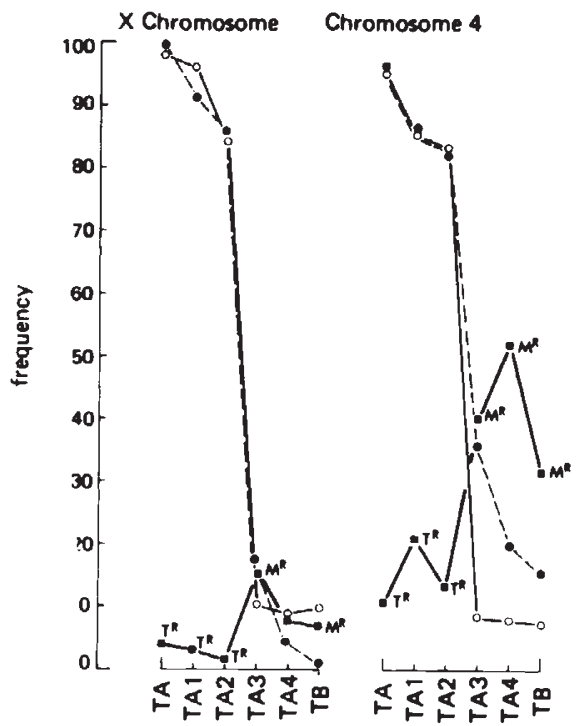

b

\section{Chromosome 6}


of Webb (1976). After removal of the alimentary canal, the carcasses were then coded and snap frozen in liquid nitrogen prior to electrophoretic analysis. Four enzyme systems known to be diagnostically different between the Moreton and Torresian taxa (Mpi, Idh-1, Got-2 and Pgi), were analysed using the method of Daly et al. (1981).

For the karyotypic analysis at least four Cbanded metaphase cells with non-overlapping chromosomes were analysed per individual (fig. 1a-f). Cells were photographed and the karyotypic composition was determined according to the criteria of Coates and Shaw (1982). The C-banding analysis of metaphase cells permitted the identification of both recombinant and non-recombinant chromosomes of the Moreton $\left(M^{R}\right.$ and $\left.M^{N}\right)$ and Torresian $\left(T^{R}\right.$ and $\left.T^{N}\right)$ taxa within each sample from the hybrid zone (see fig. 1 Shaw et al., 1982).

Egg pods were incubated at $30^{\circ} \mathrm{C}$ when development was completed in $28 \pm 1$ days. After eclosion, and prior to feeding, hatchlings were anaesthetised with $\mathrm{CO}_{2}$ and individually weighed. All egg pods were then dissected to assess the remaining number of inviable eggs. For each of the transect samples, at least 200 hatchlings were weighed and at least 40 egg pods per sample site were examined.

\section{RESULTS}

\section{(a) Chromosomal frequencies}

Comparisons of the frequencies of chromosomes $1,2, X, 4,5$ and 6 at each sample site across the zone for 1977 and 1983 are shown in fig. 2 a-c. In general, there is a consistent similarity in the frequencies of these chromosomes between years with major and concordant changeover in frequencies remaining between TA-2 and TA-3. Chromosomes 4 and 5 show a reduction in the frequency of Torresian homozygotes at TA-3, TA-4 and TB on the Moreton side of the zone (fig. $2 b$ and $c$ ). However, on the basis of chromosomal frequencies the hybrid zone has retained its overall location over the 6 year period.

The application of the C-banding technique permits the recognition of recombinant and nonrecombinant chromosomes for both the Torresian and Moreton genomes and thus provides a measure of the amount of introgression of the distal chromosomal regions marked by the interstitial and terminal bands of heterochromatic (fig. 2a-c).

In the majority of cases it is clear that there is considerable asymmetry in the distribution of re- combinants across the zone with much higher frequencies on the Moreton side. In samples TA-3 and TB, between 40 and 58 per cent of the Moreton metacentric chromosome 5 and 32-54 per cent of Moreton chromosome 4 are present in recombinant forms.

\section{(b) Gametic disequilibrium}

Moran (1979) established that the asymmetry of the hybrid zone was principally a result of selection removing interchromosomal recombinants as shown by the marked differences in the patterns of gametic disequilibria on either side of the null point. Thus those samples at TA-1 and TA-2 showed highly significant levels of interactions between most pairs of non-homologous chromosomes whereas in the equivalent populations on the Moreton side, the majority of chromosomes were at equilibrium frequencies.

Because the gametic determinant, $D$, is sensitive to marginal chromosomal frequencies (Sved, 1971), the analysis of the 1977 and 1983 data has been performed using $\operatorname{Tr}^{2}$ to estimate levels of significance which approaches to $\chi^{2}$ distribution with 1 degree of freedom (Hill and Robertson, 1968). Since recombination is at its maximum value when investigating interactions between nonhomologous chromosomes, and our sample sizes within the hybrid zone range from $30-40$ per population then the value $4 N c$ will be large. Hence $T r^{2}$ should closely approximate the $\chi^{2}$ distribution (Golding, 1984). These data are presented in table 1 and clearly indicate that a major change in both the pattern and distribution of gametic disequilibria has taken place between 1977and 1983. It appears that the entire structure of the zone-in terms of chromosomal interactions-has been reversed over this 6 year period. This is most clearly seen in the distributions of $D^{\prime}$ (per cent of $D_{\max }$ ) and in the distribution of " $r$ " $(=D /[p(1-p) q(1-$ $q)]^{1 / 2}$ ) the average correlation between individual chromosomes with the remainder of the genome (fig 3a and b). The distribution of " $r$ " for 1983 is almost a complete reversal of the pattern observed in 1977 with only the TA-2 sample showing similar values between years.

These data indicate that highly significant changes have taken place within the zone despite the fact that overall chromosomal frequencies have remained relatively constant. Furthermore, an examination of the distribution of chromosomal genotypes between years across the zone indicates considerable differences in genotypic frequencies (fig. $4 a-d$ ). On the Moreton side of the zone, there 
Table 1 Comparisons of $\mathrm{Tr}^{2}$ values with 1 d.f. calculated for pairwise interchromosomal associations observed across the hybrid zone in 1977 and 1983. ( $\mathrm{T}=$ sample size; $\mathrm{r}=$ correlation of chromosome frequencies.) Note that Moran (1979) did not use chromosomes 7,8 and 10 in his analysis of gametic disequilibrium

\begin{tabular}{|c|c|c|c|c|c|c|c|c|}
\hline \multirow{2}{*}{$\begin{array}{l}\text { Chromosome } \\
\text { pair }\end{array}$} & \multicolumn{2}{|c|}{ TA-1 } & \multicolumn{2}{|c|}{ TA-2 } & \multicolumn{2}{|c|}{ TA.3 } & \multicolumn{2}{|c|}{ TA-4 } \\
\hline & 1977 & 1983 & 1977 & 1983 & 1977 & 1983 & 1977 & 1983 \\
\hline 1 and 2 & $10 \cdot 52^{* * *}$ & $0.53 \mathrm{~ns}$ & $6.05^{* *}$ & $7 \cdot 86^{* *}$ & $4.90^{*}$ & $1 \cdot 17 \mathrm{~ns}$ & $2 \cdot 10 \mathrm{~ns}$ & $1.47 \mathrm{~ns}$ \\
\hline 1 and 4 & $4.65^{*}$ & $0 \cdot 20 \mathrm{~ns}$ & $3.69 \mathrm{~ns}$ & $9 \cdot 06^{* *}$ & $1.85 \mathrm{~ns}$ & $2.46 \mathrm{~ns}$ & $0.17 \mathrm{~ns}$ & $2 \cdot 80 \mathrm{~ns}$ \\
\hline 1 and 5 & $3 \cdot 39 \mathrm{~ns}$ & $1 \cdot 15 \mathrm{~ns}$ & $2.63 \mathrm{~ns}$ & $5 \cdot 99^{* *}$ & $3.43 \mathrm{~ns}$ & $3.80 \mathrm{~ns}$ & $1.07 \mathrm{~ns}$ & $2.81 \mathrm{~ns}$ \\
\hline 1 and 6 & 3.49 ns & $0.00 \mathrm{~ns}$ & $2.63 \mathrm{~ns}$ & $4 \cdot 55^{*}$ & $2.47 \mathrm{~ns}$ & $3.02 \mathrm{~ns}$ & $0.20 \mathrm{~ns}$ & $1.94 \mathrm{~ns}$ \\
\hline 1 and 7 & - & $0.94 \mathrm{~ns}$ & - & $5 \cdot 13^{*}$ & - & $1.08 \mathrm{~ns}$ & - & $1.94 \mathrm{~ns}$ \\
\hline 1 and 8 & - & $0.76 \mathrm{~ns}$ & - & $2 \cdot 37 \mathrm{~ns}$ & - & $5 \cdot 87^{*}$ & - & $1.90 \mathrm{~ns}$ \\
\hline 1 and 10 & $3.05 \mathrm{~ns}$ & $2 \cdot 26 \mathrm{~ns}$ & $3 \cdot 10 \mathrm{~ns}$ & $3.67 \mathrm{~ns}$ & $3 \cdot 37 \mathrm{~ns}$ & $2 \cdot 56 \mathrm{~ns}$ & $1.54 \mathrm{~ns}$ & $3.00 \mathrm{~ns}$ \\
\hline 2 and 4 & $11 \cdot 30^{* * * *}$ & $1.45 \mathrm{~ns}$ & $7 \cdot 64^{* *}$ & $8 \cdot 16^{* *}$ & $0.62 \mathrm{~ns}$ & $2.42 \mathrm{~ns}$ & $0.34 \mathrm{~ns}$ & $1.34 \mathrm{~ns}$ \\
\hline 2 and 5 & $3 \cdot 32 \mathrm{~ns}$ & $0.01 \mathrm{~ns}$ & $3 \cdot 30 \mathrm{~ns}$ & $9 \cdot 18^{* * *}$ & $1.70 \mathrm{~ns}$ & $3.58 \mathrm{~ns}$ & $0.11 \mathrm{~ns}$ & $1.85 \mathrm{~ns}$ \\
\hline 2 and 6 & $4 \cdot 85^{*}$ & $1 \cdot 81 \mathrm{~ns}$ & $6.35^{* *}$ & $5 \cdot 44^{*}$ & $4 \cdot 78^{*}$ & $1.92 \mathrm{~ns}$ & $0.11 \mathrm{~ns}$ & $3.08 \mathrm{~ns}$ \\
\hline 2 and 7 & - & $0 \cdot 16 \mathrm{~ns}$ & - & $5 \cdot 80^{*}$ & - & $1.82 \mathrm{~ns}$ & - & $0.74 \mathrm{~ns}$ \\
\hline 2 and 8 & - & $1 \cdot 17 \mathrm{~ns}$ & - & $4 \cdot 77^{*}$ & - & $10 \cdot 58 * * *$ & - & $3.08 \mathrm{~ns}$ \\
\hline 2 and 10 & $5 \cdot 41^{*}$ & $0.84 \mathrm{~ns}$ & $5 \cdot 42^{*}$ & $4 \cdot 35^{*}$ & $3.02 \mathrm{~ns}$ & $3.45 \mathrm{~ns}$ & $0.34 \mathrm{~ns}$ & $6 \cdot 45^{* *}$ \\
\hline 4 and 5 & $4 \cdot 1^{*}$ & $0.03 \mathrm{~ns}$ & $3 \cdot 38 \mathrm{~ns}$ & $16 \cdot 36^{* * *}$ & $1.46 \mathrm{~ns}$ & $17 \cdot 58^{* * *}$ & $0.28 \mathrm{~ns}$ & $5 \cdot 51^{*}$ \\
\hline 4 and 6 & $3.63 \mathrm{~ns}$ & $0.04 \mathrm{~ns}$ & $4 \cdot 41^{*}$ & $4 \cdot 27^{*}$ & $0.96 \mathrm{~ns}$ & $8 \cdot 80^{* *}$ & $1.64 \mathrm{~ns}$ & 3.67 ns \\
\hline 4 and 7 & - & $1.53 \mathrm{~ns}$ & - & $6 \cdot 37^{* *}$ & - & $11 \cdot 36^{* * *}$ & - & $15 \cdot 39 * * *$ \\
\hline 4 and 8 & - & $0.38 \mathrm{~ns}$ & - & $3 \cdot 18 \mathrm{~ns}$ & - & $6 \cdot 31^{* *}$ & - & $9 \cdot 79 * * *$ \\
\hline 4 and 10 & $1.86 \mathrm{~ns}$ & $0.02 \mathrm{~ns}$ & $4 \cdot 25^{*}$ & $6 \cdot 17^{* *}$ & $2 \cdot 84 \mathrm{~ns}$ & $4 \cdot 24^{*}$ & $0.00 \mathrm{~ns}$ & $1.38 \mathrm{~ns}$ \\
\hline 5 and 6 & $0.42 \mathrm{~ns}$ & $0.06 \mathrm{~ns}$ & $4 \cdot 67^{*}$ & $5.42^{*}$ & $5 \cdot 09^{*}$ & $14 \cdot 21^{* * *}$ & $0.01 \mathrm{~ns}$ & $4 \cdot 17^{*}$ \\
\hline 5 and 7 & - & $0.01 \mathrm{~ns}$ & - & $4 \cdot 71^{*}$ & - & $7 \cdot 76^{* *}$ & - & $4 \cdot 17^{*}$ \\
\hline 5 and 8 & - & $0.57 \mathrm{~ns}$ & - & $2.55 \mathrm{~ns}$ & - & $6 \cdot 64^{*}$ & - & $4 \cdot 20^{*}$ \\
\hline 5 and 10 & $1 \cdot 13 \mathrm{~ns}$ & $0.43 \mathrm{~ns}$ & $5 \cdot 05^{*}$ & $7 \cdot 04^{* *}$ & $3 \cdot 22 \mathrm{~ns}$ & $5 \cdot 57^{*}$ & $0.00 \mathrm{~ns}$ & $3.45 \mathrm{~ns}$ \\
\hline 6 and 7 & - & $0.86 \mathrm{~ns}$ & - & $3 \cdot 57 \mathrm{~ns}$ & - & $5.98^{*}$ & - & $2.61 \mathrm{~ns}$ \\
\hline 6 and 8 & - & $0.00 \mathrm{~ns}$ & - & $4 \cdot 14^{*}$ & - & $8.41^{* *}$ & - & $4.69^{*}$ \\
\hline 6 and 10 & $1 \cdot 14 \mathrm{~ns}$ & $0.43 \mathrm{~ns}$ & $2 \cdot 27 \mathrm{~ns}$ & $5 \cdot 60^{*}$ & $4 \cdot 61^{*}$ & $5 \cdot 49^{*}$ & $0.22 \mathrm{~ns}$ & $1.79 \mathrm{~ns}$ \\
\hline 7 and 8 & - & $1 \cdot 35 \mathrm{~ns}$ & - & $2.40 \mathrm{~ns}$ & - & $4.41^{*}$ & - & $7 \cdot 37^{* *}$ \\
\hline 7 and 10 & - & $0.02 \mathrm{~ns}$ & - & $1.85 \mathrm{~ns}$ & - & $2 \cdot 60 \mathrm{~ns}$ & - & $0.84 \mathrm{~ns}$ \\
\hline 8 and 10 & - & $0.68 \mathrm{~ns}$ & - & $2.40 \mathrm{~ns}$ & - & $9 \cdot 17^{* * *}$ & - & $1.77 \mathrm{~ns}$ \\
\hline
\end{tabular}

is a consistent and significant reduction in the frequencies of heterozygotes accompanied by a significant compensatory increase in the frequencies of the Moreton metacentric chromosomes 1, 4 and 5 . In complete contrast, on the Torresian side most of the genotypic frequencies have remained remarkably constant. This difference between the Moreton and Torresian sides is not seen for all chromosomes. Chromosome 2 shows no change in genotypic frequencies between years at any of the sites across the zone (fig. 4b). Unfortunately, similar analyses cannot be carried out for chromosomes 7 and 8 since Moran (1979) did not use the $C$-banding technique and consequently was unable to distinguish these two autosomes.

\section{(c) Allozyme Variation}

The Moreton and Torresian taxa show diagnostic differences in the frequencies of alleles at five allozyme loci (Daly et al., 1981). The pattern of variation at four of these loci (Mpi, Pgi, Idh-1 and Got-2) have been analysed in all samples across the hybrid zone. The changes in frequency for the diagnostic allele at each locus are shown in fig. 5a-d. Like the chromosomal data the major change in allele frequency for all four systems occurs between TA-2 and TA-3.

Since both chromosomal and allozymic data were obtained from the same individual, it is feasible to look for correlations between alleles and chromosome markers (interstitial heterochromatin and pericentric rearrangements), and hence suspected linkage. In fact, no such correlations were found indicating that none of the allozyme loci are tightly linked to any of the chromosomal markers but appear to be segregating quite independently. This independance was clearly seen in the case of three individuals from the TA-1 sample which were chromosomally Torresian but all three carried alleles derived from the Moreton taxon. A more thorough investigation of the relationship between allozyme loci and chromosomal markers will be made in the future. 


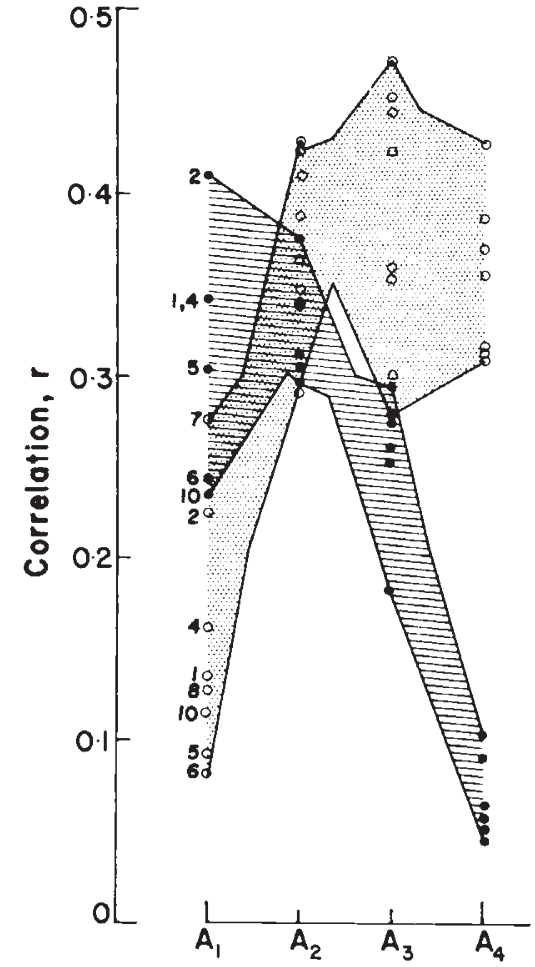

a

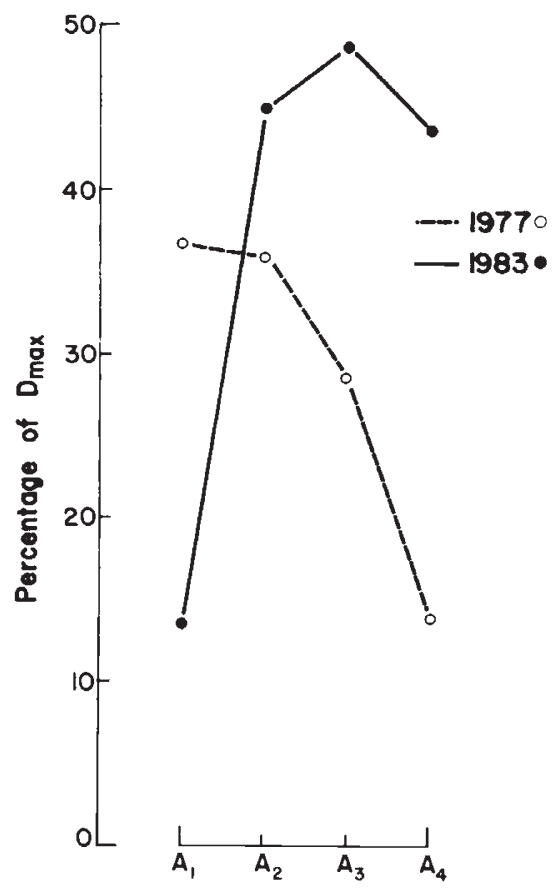

b

Figure 3 (a) The distribution of the correlation $(r)$ between each autosome with the remainder of the genome at each site across the hybrid zone. The striped area represents the data for 1977 and the spotted is 1983 . The distributions show a reversal between years. (b) a comparison of the distribution of $D^{\prime}$ (per cent of $D_{\max }$ ) between years which again shows a reversal in distribution pattern between years.

\section{(d) Embryonic weight at eclosion}

The distribution of eclosion weights across the hybrid zone is presented in fig. 6. An analysis of variance of these data reveals that there is a highly significant change in weight between TA-2 and TA-3. Those samples located on either side of TA-2 and TA-3 are homogeneous and not significantly different from the embryonic weights obtained among samples from pure Torresian and Moreton populations. It should be emphasised that this difference of 20 per cent in body weight does not reflect any differences in developmental time since embryogenesis was completed in $28 \pm 1$ days in both taxa.

In order to assess the correlation between karyotype and embryonic weight, a selection experiment was undertaken using 283 embryos from the TA-2 sample. Chromosomally, this sample is predominantly Torresian and selection was practised for the smallest embryos (less than $55 \mathrm{mg}$ ) and those closest to the mean weight $(65-75 \mathrm{mg})$. The chromosomal characteristics of these selected individuals were then assessed in terms of the number of pericentric rearrangements per individual genome which consists of 23 chromosomes in the male and 24 in the female (table 2). It was found that the small embryo class of 10 selected individuals had a mean number of 10.7 rearrangements per individual. This compared with the mean of $3 \cdot 2$ for those 23 embryos weighing between 65 and $75 \mathrm{mg}$. The average number of rearrangements per individual in TA- 2 is 3.1 and the mean embryonic weight is $70.7 \mathrm{mg}$. When one considers that the probability of obtaining an individual with 10 or more rearrangements in the TA-2 sample is $0 \cdot 1$ then it seems clear that there exists an extremely strong relationship between embryonic weight and chromosomal structure.

\section{(e) Embryonic Viability across the Hybrid Zone}

The mean viabilities of eggs derived from females at each sampling location within the hybrid zone and from the pure parental populations are shown 

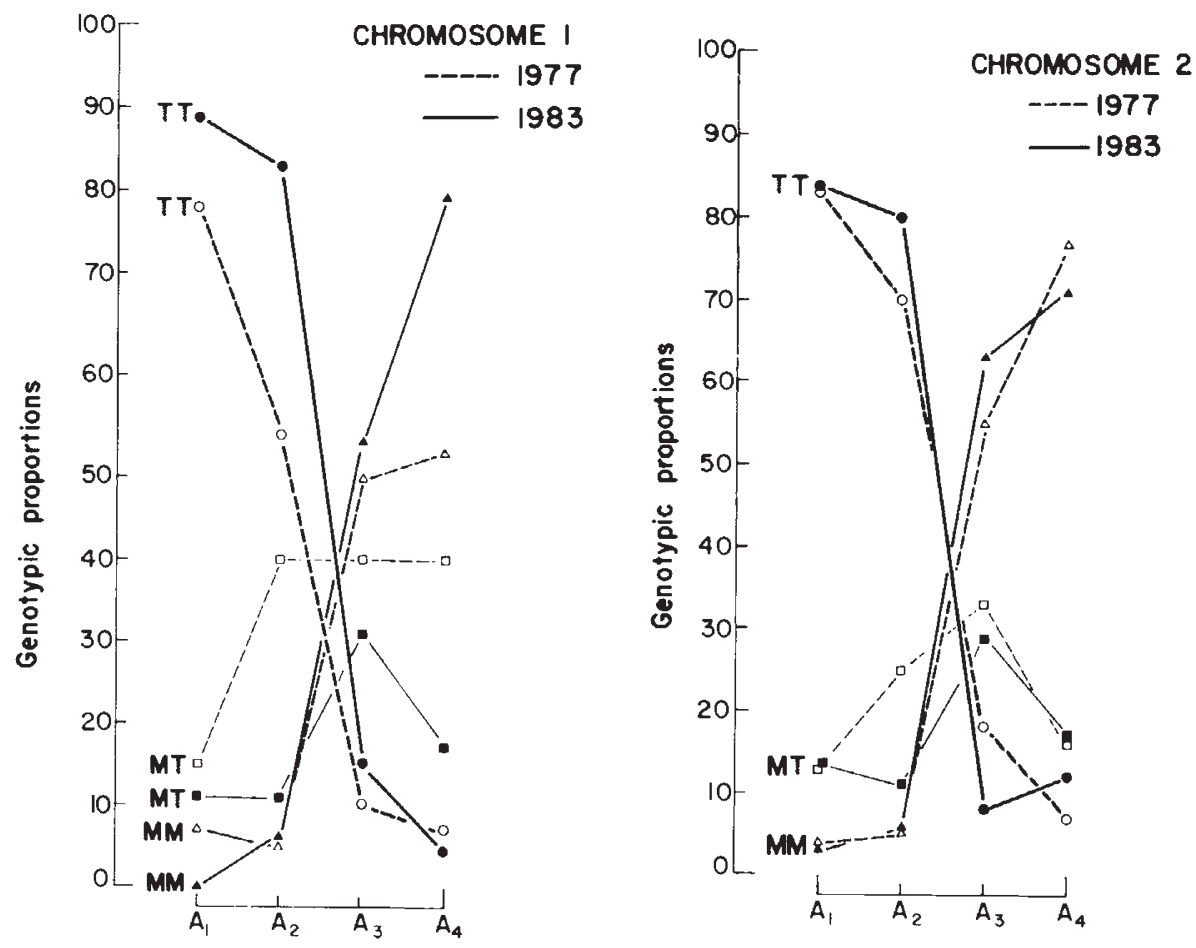

a

b
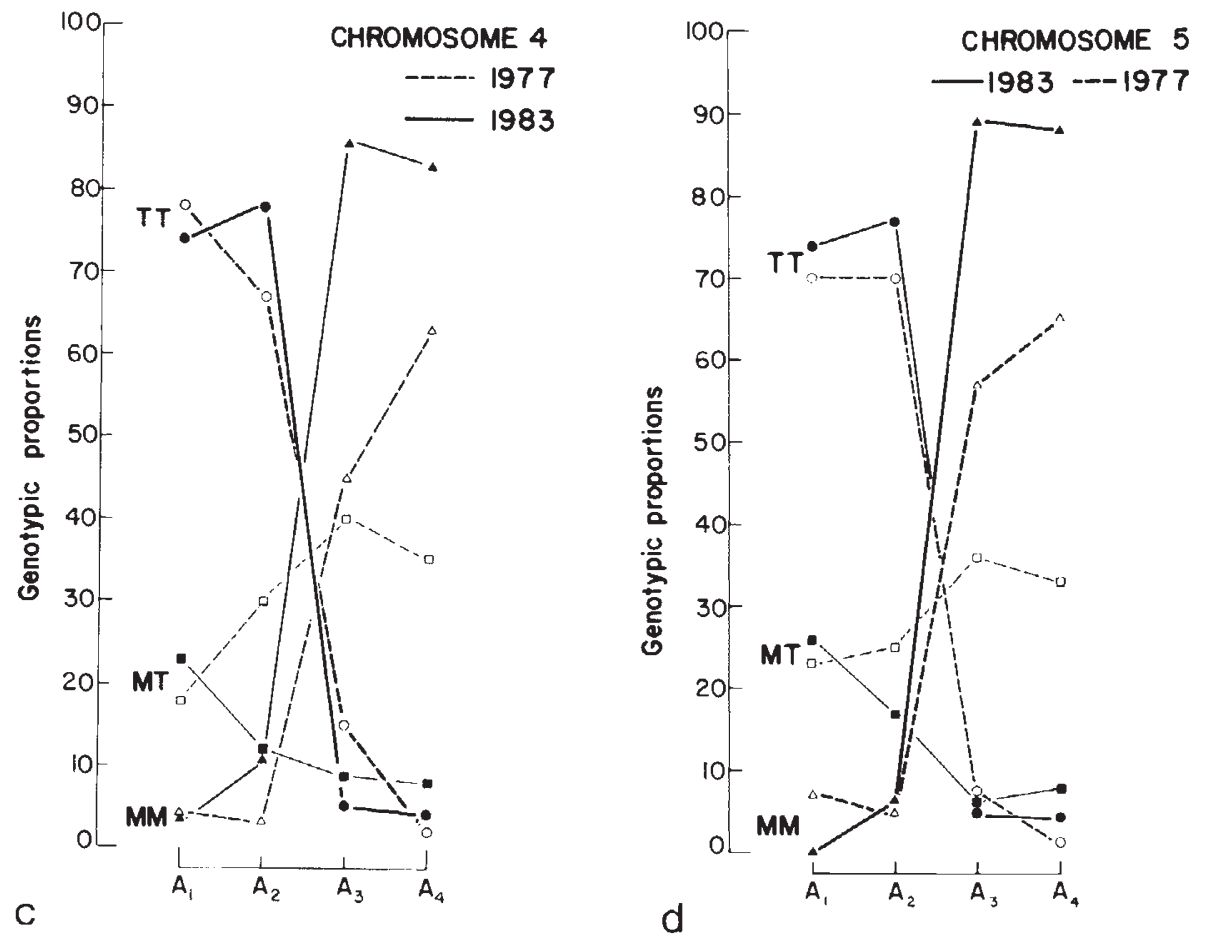

Figure 4a-d Patterns of genotypic frequencies found across the hybrid zone between 1977 and 1983. The reduced frequencies of heterozygotes in (a), (c) and (d) and the increases in metacentric homozygotes in $\mathrm{TA}_{4}$ are all significant. Note that the genotypic proportions at TA-1 have remained unchanged between years. Chromosome $2(\mathrm{~b})$ also shows no change in frequencies across the zone $(\mathrm{TT}=$ Torresian homozygote, $\mathrm{MT}=$ Heterozygote, $\mathrm{MM}=$ Moreton homozygote $)$. 


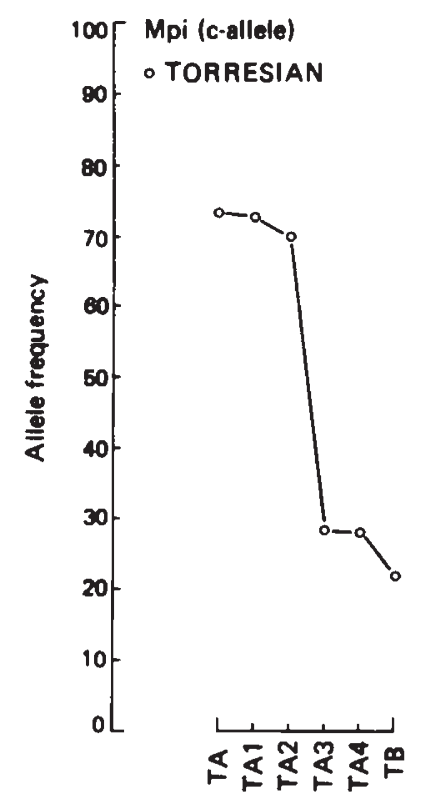

a

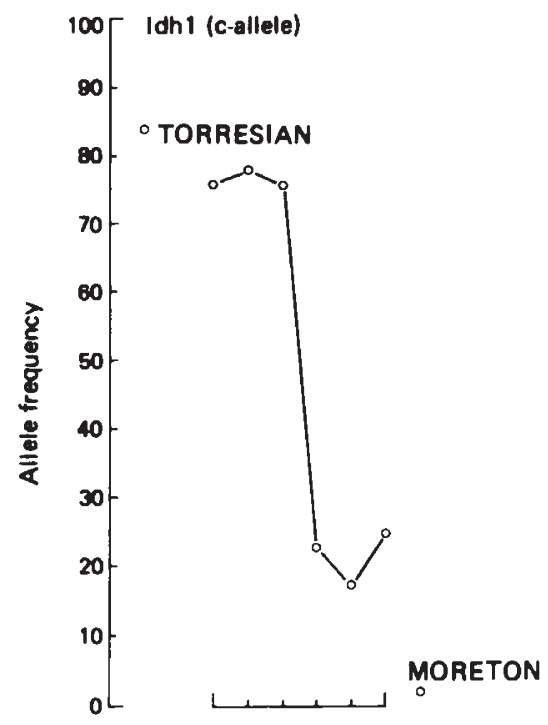

C

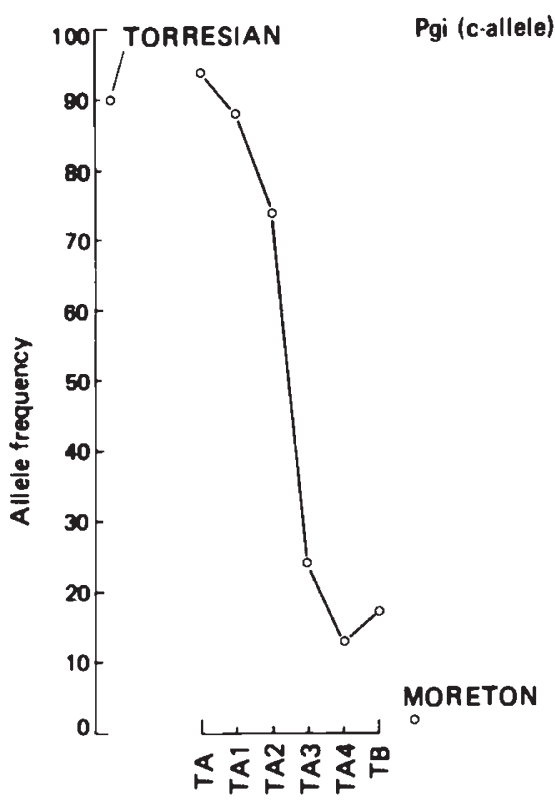

b

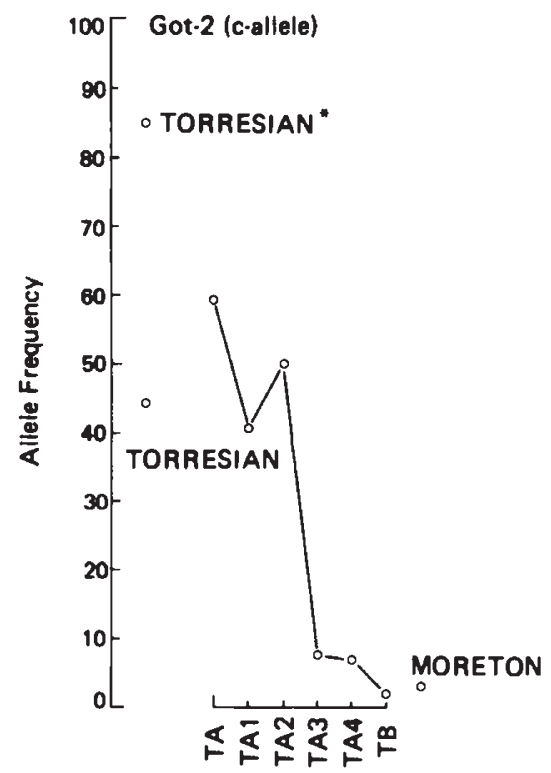

d

Figure 5a-d The changes in frequency of the diagnostic Torresian allele for (a) Mpi, (b) Pgi, (c) Idh-1 and (d) Got-2 across the hybrids. The marked changes in frequency between TA-2 and TA-3 are concordant with the changes in chromosomal frequencies. (*the two frequencies for the Torresian $C$-allele in (d) represent its frequency in two different Torresian populations). 
Table 2 The results of a selection experiment for embryonic weight practised upon the TA-2 sample which is chromosomally predominantly Torresian. Individuals with weights close to the population mean of $70.2 \mathrm{mg}$ and those with low weights $(<55 \mathrm{mg})$ were scored for the frequencies of rearrangements per individual

\begin{tabular}{lcll}
\hline & $\begin{array}{l}\text { Base } \\
\text { population } \\
\text { (TA-2) } \\
n=283\end{array}$ & $\begin{array}{l}\text { Selected } \\
\text { line } \\
(\text { Mean }) \\
n=23\end{array}$ & $\begin{array}{l}\text { Selected } \\
\text { line } \\
\text { (Low) } \\
n=10\end{array}$ \\
\hline $\begin{array}{l}\text { No. of rearrange- } \\
\text { ments per individual } \\
\begin{array}{l}\text { Mean embryonic } \\
\text { weight at hatching }\end{array}\end{array}$ & $3 \cdot 1$ & $3 \cdot 2$ & $10 \cdot 7$ \\
\hline
\end{tabular}

in fig. 6. There is a highly significant reduction in viability between TA- $2(\bar{x}=83$ per cent $)$ and TA-3 $(\bar{x}=56$ per cent $)$. At TA -4 the mean viability is still only 70 per cent whereas at TB the viability value of 83 per cent is very close to that observed in the pure Torresian and Moreton populations.

\section{DISCUSSION}

\section{(a) Karyotypic variation within the hybrid zone}

This temporal analysis of the hybrid zone between the Moreton and Torresian taxa has clearly demon- strated that the zone can change its genotypic composition quite dramatically over a period of only six generations. Furthermore, the changes involve a considerable proportion of the genome, are directional and asymmetrical. The components of gametic disequilibria involving most members of the genome have systematically changed even though recombination (involving non-homologous chromosomes) is at its maximal value of 0.5 . Such a change in the patterns of disequilibria can be interpreted in terms of natural selection, genetic drift or migration. We consider that the major factor responsible for such intense changes in genotypic composition can be attributed to the action of natural selection for the following reasons. First, there is no evidence to indicate that population sizes have undergone any major reductions during the period 1977-1983. Secondly, the asymmetrical nature of the observed changes in chromosomal genotypic frequencies tends to negate the influence of drift, as does the observation that the changes are directional and concerted involving several members of the genome. Thirdly, differential migration can also be discounted as a major factor since the frequencies of pure parental genotypes on both sides of the zone have remained constant between years. Similarly, the constancy of genotype frequencies for chromosome 2

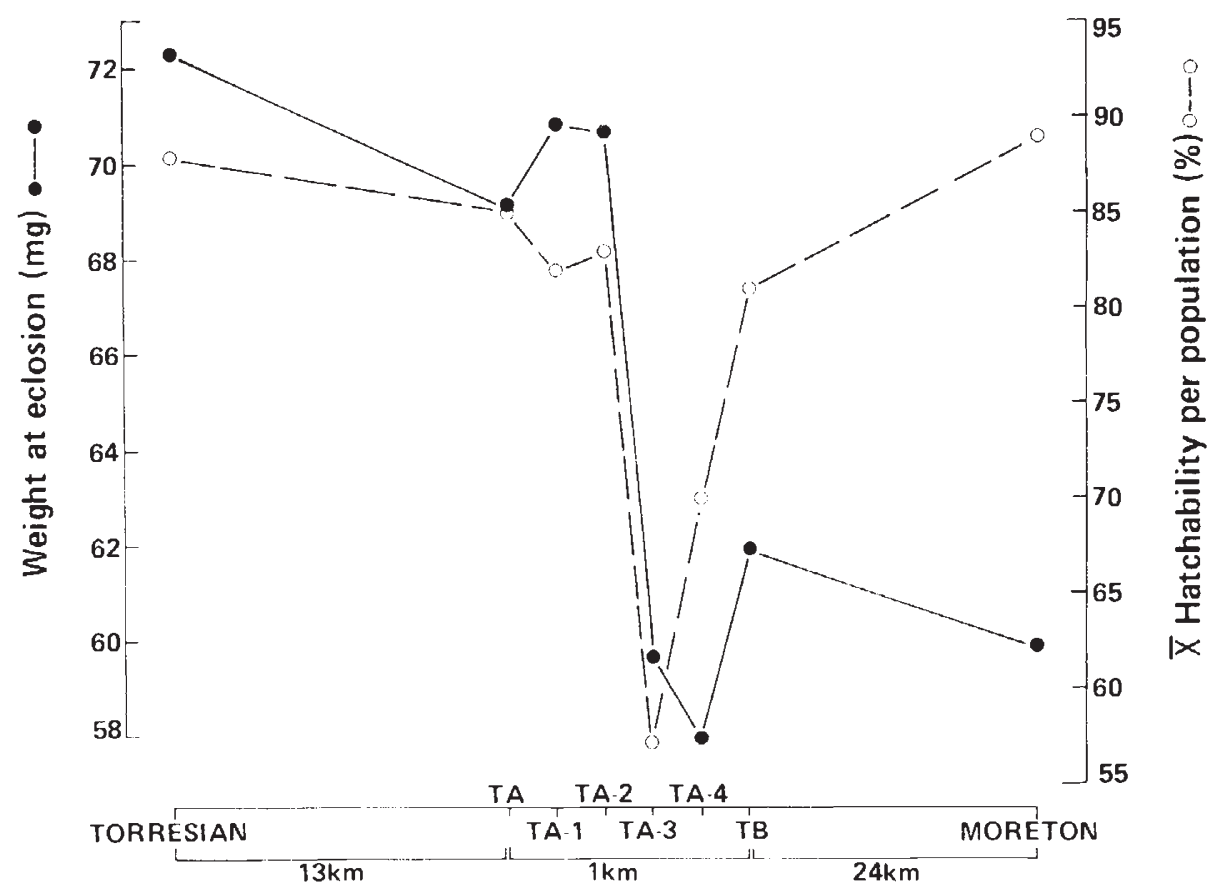

Figure 6 The changes to the patterns of embryonic weight and egg viabilities across the hybrid zone. The marked change from high embryonic weight (Torresian) to low weight (Moreton) is concordant with the changes observed for chromosomes and allozymes. Note the significantly reduced viabilities among egg samples at locations TA-3 and TA-4. 
between years (fig. 4b), indicates the insignificant influence of migration. The high frequency of recombinant chromosomes on the Moreton side of the zone again suggests that migration is not a principal factor but one cannot discount the combined effects of both migration and selection. Even then, however, such high frequencies of recombinant chromosomes on the Moreton side after migration would still necessitate the influence of intense selection.

The observed changes can be most readily interpreted in terms of the action of strong directional selection favouring a metacentric karyotype on the Moreton side of the zone. Furthermore, the asymmetrical nature of the response seems to indicate the influence of environmental factors rather than disruption to the "internal" genetic environment (Clark, 1968).

It is clear that there are two independent phenomena which are acting to structure the zone. First, Coates and Shaw (1982) and Shaw et al., (1982) have previously shown that the major effect of pericentric hererozygosity in $F_{1}$ hybrids involves a redistribution of chiasmata during meiosis. This, in turn, generates an array of novel recombinant chromosomes which are generally less fit than the parental chromosomes. This reduced fitness of the $F_{1}$ gametes accounts for approximately 50 per cent of the total $\mathrm{F}_{2}$ inviability (Shaw and Coates, 1983). Moreover, genome analysis of the backcross progeny reveals that the inviability is attributable to intra-chromosomal effects with no evidence of inter-chromosomal interactions like those observed in the hybrid zone in this study and by Moran (1979). This secondary feature of the chromosomal differentiation which distinguishes the Moreton and Torresian taxa sufficiently explains the establishment of the hybrid zone as hybridisation would generate a difference in chromosomal frequency of approximately 50 per cent for each diagnostic chromosome due to compulsory backcrossing.

In contrast, a direct and primary genetic role for the fixed chromosomal differences which distinguish the two taxa may relate more to external or environmental factors, since the changes in genotypic frequencies between years are associated with a major environmental perturbation over the same period. When Moran (1979) sampled the zone in 1977, S.E. Queensland was experiencing its worst drought on record. The annual rainfall was reduced to about half the normal precipitation level (fig. 7). Analysis of Bureau of Meteorology rainfall records for the region reveals that the general area occupied by the Moreton taxon receives on average, almost twice the amount of rainfall than does the Torresian region $(1600 \mathrm{~mm}$ vs $900 \mathrm{~mm}$ ). This difference in annual precipitation is also associated with much greater variation in the predictability of rainfall in the Torresian (fig. 7).

This pattern of rainfall variation correlates well with both the overall distributions of the Moreton and Torresian taxa and with the observed changes within the hybrid zone. Thus the regional rainfall differences follow approximately the distributions of the two taxa, producing an "area effect" which delimits them into broad environmental zones. However, there is no sharp ecotonal change in rainfall to coincide with the hybrid zone since the transition from mesic (Moreton) to arid (Torresian) occurs over a distance of approximately $30 \mathrm{~km}$ with the zone itself located well within the arid region. The clear implication here is that the Moreton taxon may have moved westward, a suggestion which is reflected in the polymorphisms for acrocentric chromosomes which characterise those Moreton populations proximal to the hybrid zone (Moran and Shaw, 1977; Moran, 1979).

If natural selection favours an acrocentric karyotype in the drier region then, at the time of Moran's analysis, the disequilibrium observed on the Torresian side of the zone may reflect the selective removal of introgressed Moreton chromosomes from these populations. At the same time, selection would be less effective on the Moreton side since acrocentric (Torresian) chromosomes occur at much lower frequencies. Thus if selection is acting upon genomes, as indicated by the high levels of interchromosomal interactions, rather than single chromosomes, then low frequencies of polymorphisms will be insufficient for selection to be effective. A subsequent return to normal patterns of rainfall would be accompanied by a reversal of the selection process which now favours the metacentric karyotype on the Moreton side of the zone. That is, the return to a normal rainfall pattern is accompanied by positive directional selection on the Moreton side with very little effect upon the genotypic frequencies on the Torresian side.

\section{(b) An adaptive role for karyotypic reorganisation}

Previous attempts to ascribe adaptive functions to chromosomal rearrangements have emphasised the significance of chromosomal variation solely in terms of genic parameters or their influence upon genic parameters (Dobzhansky, 1970), such 


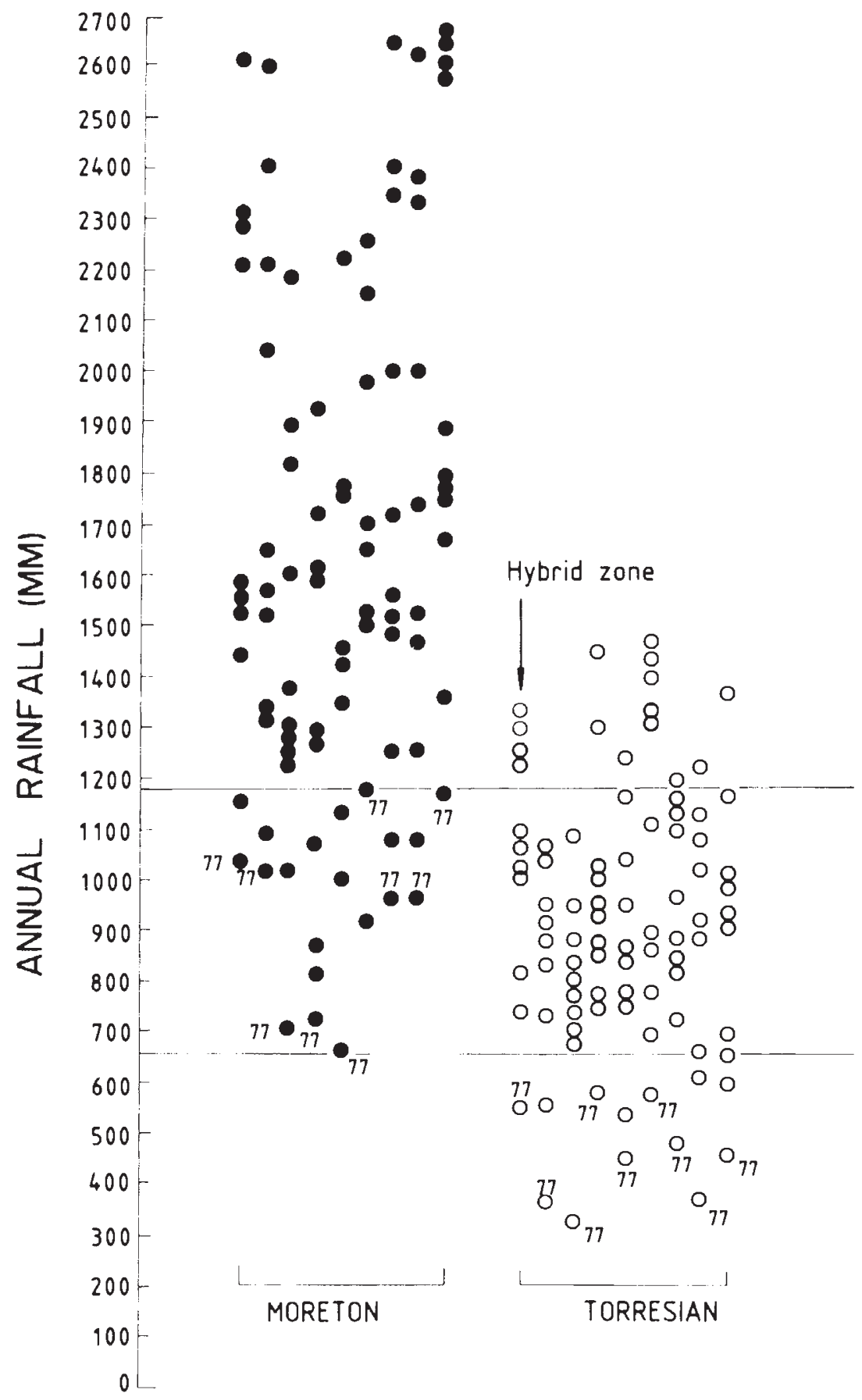

Figure 7 The patterns of annual rainfall in both the Moreton and Torresian geographic regions. In 1977 when Moran sampled the hybrid zone the region experienced a severe drought. Note that the rainfall pattern at the hybrid zone is Torresian (arid) in character. The lower annual rainfall pattern in the Torresian region is also accompanied by a greater seasonality of rainfall which limits this taxon to only one generation a year. 
as the preservation of relationally balanced homologues by inversion heterozygosity and balanced polymorphism. Chromosomal homozygosity has received relatively little attention as an adaptive characteristic, mainly because of this preoccupation with genic interpretations. Indeed, it is generally assumed that chromosomal homozygosity is the result of the chance fixation of negatively heterotic rearrangements in small isolated demes (for review see Patton and Sherwood, 1983).

We consider that there is some indirect evidence to indicate that chromosomal patterning may form part of an adaptive strategy in which the structure of the karyotype plays an integral role. The homozygous metacentric karyotype of the Moreton taxon represents the northern endpoint of a cline for metacentric chromosomes which extends for over $1700 \mathrm{~km}$ to southern Victoria which has an acrocentric karyotype equivalent in gross morphology to the Torresian (Shaw and Coates, 1983). In between these two extremes, the populations are polymorphic and show a gradual change in the relative frequencies of metacentric chromosomes. Moreover, not only does the frequency of acro- and metacentric chromosomes change along the cline, but the position of the centromere also moves towards the centre of the chromosome as one progresses north (Shaw et al., in prep.). This results in three to six different morphs of biarmed chromosomes for each homologue in the complement and leads to highly complex patterns of polymorphisms within the population.

This north-south cline is correlated with a gradual change in the frequency of bivoltine (northern) and univoltine (southern) generation patterns. In central New South Wales, for instance, there are two generations-one summer and the other winter. However, the latter is characterised by much reduced population densities when compared with the former. As one moves south, the abundance of winter individuals diminishes until at Lakes Entrance in southern Victoria, adults are found only during the summer period, similar to the life history characteristics of the Torresian taxon. In this regard the Lakes Entrance embryos attain similar weights to those found in the Torresian, and furthermore both share similar acrocentric karyotypes (Shaw et al., 1982).

It should be recalled that across the hybrid zone there is also a marked change in the final embryonic weight which coincides with the major change in chromosomal frequencies. Moreton embryos are approximately 20 per cent lighter than the Torresian. Although this correlation between weight and karyotype may simply reflect the coincidence of two independent systems, the results of the selection experiment for embryonic weight reveal that they may be more casually related. The chance of obtaining 10 selected embryos containing 10 or more rearrangements per individual is extremely low if the two systems are independent. From the observed results one has to imply that the genic factors responsible for the embryonic weight differences are largely clustered within the limits of the chromosomal rearrangements involving most members of the genome. This seems very unlikely unless one postulates that the genic factors are all located within the same pericentromeric region of each non-homologous chromosome.

Alternatively, Coates and Smith (1985) and Coates and Wilson (1985) have demonstrated that some chromosomes within the Moreton genome are arranged non-randomly at metaphase which is thought to reflect a fixed spatial arrangement during the cell cycle. It is a strong possibility that the physical constraints associated with the maintenance of these chromosome configurations and the packaging of chromosomes within the nucleus may be fundamental features of karyotypic structure. Thus the transformation of the acro/ telocentric chromosomes of the Torresian genome into metacentric elements in the Moreton alters quite significantly the relationship between the telomeres and centromeres if either or both are attached at fixed positions on the nuclear membrane. In fact, there is good evidence to indicate that certain defined features of the chromosomecentromeres, telomeres and constitutive heterochromatin-interact with the nuclear envelope in a very specific way (Comings, 1980). In particular, the centromeres and telomeres are thought to be attached to the nuclear envelope at fixed locations which are only disrupted during cell division (Franke, 1974). Even then, it has been shown that pieces of the nuclear envelope remain attached to the chromosomes (Stubblefield and Wray, 1971). Thus it follows that the marked differences in chromosomal organisation between the Moreton and Torresian subspecies may also reflect differences in spatial organisation of chromatin within the nucleus. In this way, it is much easier to consider the influence of chromosomal rearrangements as modifiers of cellular parameters and developmental profiles. Hence the difference in final embryonic weight between the acrocentric karyotypes of Lakes Entrance and Torresian and the metacentric Moreton karyotype may simply reflect different strategies in patterns of cell division giving smaller cells in the Moreton subspecies. The 
chromosomal polymorphisms seen in the populations in New South Wales may add a high degree of flexibility to the developmental system in less predictable environments. The possible relationship between chromosomal rearrangements and cell cycle parameters, such as DNA replication patterns, nuclear and cellular volume, centromere and telomere disposition at interphase, is presently under investigation.

Acknowledgements We would like to thank Maureen Whittaker and Gary Brown for their preparation of the photographs and illustrations presented in this paper.

\section{REFERENCES}

ARNOLD, M. L., APPELS, R. AND SHAW, D. D. 1985. The heterochromatin of grasshoppers from the Caledia captiva species complex 1 . Sequence evolution and conservation in a highly repeated DNA family. $\mathrm{Mol}$. Biol. Evol. (In press).

AVISE, J. C. 1976. Genetic differentiation during speciation. In Molecular Evolution (ed. F. J. Ayala) Sinauer, Mass, pp. 106-122.

BUSH, G. 1975. Modes of animal speciation. Ann. Rev. Ecol. Syst., 6, 339-364.

CARSON, H. L. 1973. Reorganisation of the gene pool during speciation. In Genetics of Natural Populations (ed. N. E. Moreton) Monograph III, Univ. Hawaii, pp. 274-280.

CHARLESWORTH, B., LANDE, R. AND SLATKIN, M. 1982. A neo-Darwinian Commentary on Macroevolution. Evolution, 36, 474-498.

CLARKE, B. C. 1968. Balanced polymorphism and regional differentiation in land snails. In "Evolution and Environment" (ed. E. T. Drake) Yale Univ. Press. New Haven.

COATES, D. J. AND SHAW, D. D. 1982. The chromosomal component of reproductive isolation in the grasshopper Caledia captiva 1. Meiotic analysis of chiasma distribution patterns in two chromosomal taxa and their $F_{1}$ hybrids. Chromosoma, 86, 509-531.

COATES, D. J. AND SMITH, D. 1984. The spatial distribution of chromosomes in metaphase neuroblast cells from subspecific $F_{1}$ hybrids of the grasshopper Caledia captiva. Chromosoma, 90, 338-348.

COATES, D. J. ANDS. R. WIISON. 1985. The spatial organisation of chromosomes within haploid genomes of the grasshopper Caledia captiva. Cytobios, (in press).

COMINGS, D. E. 1980. Arrangement of chromatin in the nucleus. Hum. Genet., 53, 131-143.

DALY, J. C, WILKINSON, P. AND SHAW, D. D. 1981. Reproductive isolation in relation to allozymic and chromosomal differentiation in the grasshopper Caledia captiva. Evolution, 35, 1164-1179.

DOBZHANSKY, TH. 1950. Origin of heterosis through natural selection in population of Drosophila pheudoobscura. Genetics, 35, 288-302.

DObZhanSKy, TH. 1970. Genetics of the Evolutionary Process. Columbia Univ. Press. New York pp. 505.

FRANKE, W. W. 1974. Structure, biochemistry and functions of the nuclear envelope. Int. Rev. Cytol. suppl. 4 (ed. G. H. Bourne and J. F. Danielli), 72-211.

GOLding, G. B. 1984. The sampling distribution of linkage disequilibrium. Genetics, 108, 257-274.

GOULD, S. J. 1980 . Is a new and general theory of evolution emerging? Paleobiology, 6, 119-130.
GOULD, S. J. AND ELIRRIDGE, N. 1977. Punctuated equilibria: the tempo and mode of evolution reconsidered. Paleobiology, 3, 115-151.

HILL, W. G., ROBERTSON, A. 1968. Linkage disequilibrium in finite populations. Theor. Appl. Genet., 38, 226-231.

LANISE, R. 1979. Effective deme sizes during long term evolution estimated from rates of chromosomal rearrangement. Evol ution, 33, 234-251.

I.ANII:, R. 1984. The expected fixation rate of chromosomal inversions. Evolution, 38, 743-752.

LEVINTON, J. S. AND SIMON, C. M. 1980. A critique of the punctuated equilibria model amd implications for the detection of speciation in the fossil record. Syst. Zool., 29, $130-142$.

MAYNARD SMITH, J. 1983. The genetics of stasis and punctuation. Ann. Rev. Genet, 17, 11-25.

MAYR, E. 1975. The unity of the genotype. Biol. Zbl., 94, 377388.

MAYR, E. 1982. Adaptation and selection. Biol. Zbl., 101, 161174.

MORAN, C. 1979. The structure of the hybrid zone in Caledia captiva. Heredity, 42, 13-32.

MORAN, C. AND SHAW, 1). D. 1977. Population cytogenetics of the genus Caledia (Orthoptera Acridinae). III Chromosomal polymorphism, racial parapatry and introgression. Chromosoma, 63, 181-204.

PATTON, J, L. AND SHER WOOD, S. W. 1983. Chromosome evolution and speciation in rodents. Ann. Rev. Ecol. Syst., 14, 139-158.

PAVLOVSKY, O. AND DOBZHANSKY, TH. 1966. The coadapted system of chromosomal variants in a population of Drosophila pseudoobscura. Genetics, 53, 843-854.

SHAW, D. D. 1976. Population cytogenetics of the genus Caledia (Orthoptera: Acridinae). 1. Inter-and intraspecific karyotype diversity. Chromosoma, 54, 221-243.

SHAW, D. D. AND COATES, D. J. 1983. Chromosomal variation and the concept of the coadapted genome-a direct cytological assessment. In Kew Chromosome Conference II (ed. P. E. Brandham and M. D. Bennett) p. 207-216.

SHAW, D. D. AND WILKINSON, P. 1980. Chromosomal differentiation, hybrid breakdown and the maintenance of a narrow hybrid zone in Caledia. Chromosoma, 80, 1-31.

SHAW, D. D., WILKINSON, P. AND COATES, D. J. 1982. The chromosomal component of reproductive isolation in the grasshopper Caledia captiva. II. The relative viabilities of recombinant and non-recombinant chromosomes during embryogenesis. Chromosoma, 86, 533-549.

STUBBLEFIELD, E. AND WRAY, W. 1971. Architecture of the Chinese Hamster metaphase chromosome. Chromosoma, 32, 262-294.

SVIII, J. A. 1971. Linkage disequilibrium and homozygosity of chromosome segments in finite populations. Theor. Pop. Biol., 2, 125-141.

WEBB, G. C.. 1976. Chromosome organisation in the Australian plague locust, Chortoicetes terminifera 1 . Banding relationships of the normal and supernumerary chromosomes. Chromosoma, 55, 229-246.

WHITE, M. J. D. 1975. Chromosomal repatterning-regularities and restrictions. Genetics, 79, 63-72.

WhITE, M. J. D. 1978. Modes of Speciation. Freeman, San Francisco.

WHITE, M. J. I), BIACKITH, R. E., BLAC:KITH, R. M. AND CHENEY, J. 1967. Cytogenetics of the viatica group of morabine grasshoppers 1. The coastal species. Aust. J. Zool., 15, 263-302.

WRIGHT, s. 1941. On the probability of fixation of reciprocal translocations. Am. Nat., 75, 513-522. 